\title{
Ethics review procedures for research in developing countries: a basic presumption of guilt
}

\author{
Robert H. Gilman, Hector H. Garcia
}

T There is a marked disparity between the burden of disease in developing countries and the proportion of medical research that is devoted to the diseases of the developing world. ${ }^{1}$ Although it is heartening that $25 \%$ of scientific publications result from work in developing countries, ${ }^{2}$ much more needs to be done. One of the obstacles to research in developing countries is the complex process of ethical approval for studies, particularly those funded by institutions and industrial sponsors in developed countries. The point has often been made that research in developing countries poses particular ethical issues, ${ }^{3,4}$ but our experience of more than 18 years of collaborative research in Peru persuades us that efforts to provide ethical oversight of research in developing countries are often duplicated unnecessarily and are frequently based in trivial, misplaced or simply invalid concerns.

Institutional review boards (IRBs) in developed and developing countries tend to operate on the presumption that investigators are intent on exploiting disadvantaged and poorly educated subjects. This perception has given rise to an ethics review system for international research that is unnecessarily complex and legalistic. This exaggerated response is detrimental to the promotion of research in developing countries and does not result in better protection for research subjects.

Collaborative studies conducted by federally funded institutions in the United States are a good example. For such studies, IRBs in the developing country are required to register with the US Office for Human Research Protections, and institutions should file a "Federalwide Assurance," a document declaring compliance with an accepted ethical standard for human research (e.g., the Helsinki Declaration). Studies can proceed only after each participating institution's IRB has reviewed and approved the proposed study and consent forms. In international research, this often involves more than one, and sometimes many, IRBs. Even the most benign study must navigate a maze of committees, setting the research process back months and even years. For example, a simple village survey study over a 5year period could require 40 separate IRB approvals (or renewals) - at a high cost of time, effort and funding.

Does a multiplicity of ethical review committees make a project more ethical? We doubt it. Rather, these committees simply entangle the process in bureaucratic delays. ${ }^{5}$ Approval by a single IRB takes between 1 and 3 months in most cases. The IRBs either approve the study or request clarifications or amendments, which might necessitate another full review. Given that each IRB has its own com- ments to make, changes requested by one IRB need to be reviewed by all other committees before final approval. Often, each institution wants the consent form written a different way. ${ }^{6}$ Thus, depending on the number of agencies and locations involved, the sheer number of reviews with their multiple consent forms (especially if children and adolescents are involved) can create a virtual paper mill. There is no hierarchy: each committee wants the last word.

In addition, annual ethics reviews are required in multiyear studies. New questions may arise. We have seen instances of ethics committees requiring changes to the language of the consent forms even though the same committee had approved the wording the previous year. Until all IRBs involved have approved the new changes, they may require researchers to stop recruiting new subjects.

Collaborative international research, as we have noted, involves approval by IRBs in the sponsoring country and in the developing country. IRBs in developed countries are nearly always paternalistic and have a low regard for the quality of IRB reviews in less developed countries - even though local committees know their local populations better and are more likely to protect and care for them. Of course, it would be naive to assume that all local IRBs can perform thorough reviews of a wide array of potential studies involving molecular biology, genetic epidemiology, spatial analysis, etc. But it would be rational to select and accredit those IRBs that can provide a good review.

Many members of IRBs in developed countries have little (if any) experience in the developing world and do not understand local constraints. Lacking both knowledge of the local culture and trusting neither the local institution nor the investigator, they may correct the language of the consent form or recommend procedures that are not culturally suitable. Discussing the wording of a consent form in English when it is to be applied in a different language is inappropriate. IRBs in developing countries may judge the wording too complex, even though the terminology is clear for people reading it in their native language.

In the United States, IRB committees are now charged not only with upholding overall ethical standards, but also with protecting the economic status and liability of their institutions. Thus they must assess collaborative studies against a labyrinth of legalistic and regulatory issues. Lengthy, complex multi-page consent forms are difficult to read. Often, their final format resembles a disclaimer more than an informative document. ${ }^{7}$

Similarly, IRBs might not approve some studies lest such approval jeopardize the institution's public image - 
even if the risks to the institution are negligible and the benefits for the study population are high. For example, one of us participated in the design of a study comparing conventional and new techniques to diagnose tuberculosis infection and drug resistance in a prison population in Peru (where multidrug-resistant tuberculosis is common). The study made provisions for appropriate treatment. IRB approval was stalled by concerns about "using" this vulnerable population. During the delay, a local collaborator relocated, which meant that the study could not proceed. The study posed no risk to the prisoners and, indeed, might have saved the lives of those with drug-resistant tuberculosis.

\section{What can be done?}

We suggest three strategies to ensure the ethical protection of human subjects in developing countries while also encouraging research. First, no more than 2 institutions should be in charge of the ethics review of international studies: the institution of the principal investigator, and the institution of the principal foreign collaborator. The more reviews there are, the more chance there is for reviewers to request new changes that will have no or little effect in protecting study subjects. Other review boards should be limited to registering and verifying the 2 IRB approvals, unless those boards have particular concerns (which the primary IRBs should address).

Second, whenever feasible, the developed country review panel should consist of people who have spent time working in the developing world.

Third, the consent document should be the one approved by the local IRB. If a back translation into the language of the sponsoring country is needed, this should not be used to assess the language level. The terminology should be expressed in the native language and by the local institution.

In both developed and developing countries, the current IRB situation is becoming unmanageable and urgently needs revision. There is now a large, built-in administrative infrastructure involved in ethical review at several levels, including funding agencies, universities, nongovernmental organizations and governmental bodies. As this infrastructure becomes more established, its members will have a vested interest in keeping the status quo or increasing the complexities of the review process. We believe this situation is detrimental to research and compromises the rights of research subjects. Funding agencies must change the current situation, since they have the power to terminate institutional research programs. ${ }^{8}$ We must redress the balance, so that the ethical process is simple, concentrates on the rights of individuals and is institutionally hierarchical. We are not arguing for an eased ethical standard, or to bypass IRB review in either developed or developing countries. We believe an equally high standard of protection could be achieved with a less legalistic and repetitive system. A thorough, stringent review by one developed and one developing country institution is sufficient to adequately protect the rights of study participants.

Drs. Gilman and Garcia are from the Department of International Health, Johns Hopkins University Bloomberg School of Public Health, Baltimore, Md., and the Department of Microbiology, School of Sciences, Universidad Peruana Cayetano Heredia, Lima, Peru. Dr. Gilman is also a Senior Investigator at the Asociación Benéfica PRISMA (Proyectos en Informática, Salud, Medicina y Agricultura) Lima, Peru.

Competing interests: None declared.

Contributors: Both authors participated equally in the preparation of this article.

\section{References}

1. Western medical journals and the $10 / 90$ problem [editorial]. CMAf 2004;170(1):5.

2. UNESCO Institute of Statistics. The state of science and technology in the world, 1996-7. Paris: UNESCO Institute of Statistics; 2001

3. Gambia Government / Medical Research Council Joint Ethical Committee. Ethical issues facing medical research in developing countries. Lancet 1998;351:286-7.

4. National Bioethics Advisory Commission. Ethical and policy issues in international research: clinical trials in developing countries. Vol I. Report and Recommendations of the National Bioethics Advisory Commission. Bethesda: The Commission; 2001. p. 138.

5. Gilman RH, Anderton C, Kosek M, Garcia HH, Evans CA. How many committees does it take to make a project ethical? Lancet 2002;60:1025-6.

6. McWilliams R, Hoover-Fong J, Hamosh A, Beck S, Beaty T, Cutting G Problematic variation in a local institutional review of a multicenter genetic epidemiology study. 7AMA 2003;290:360-6.

7. Beyer DR, Lauer MS, Davis S. Readability of informed consent forms. N Engl 7 Med 2003;348:2262.

8. Steinbrook R. Protecting research subjects: the crisis at Johns Hopkins. $N$ Engl 7 Med 2002;346:716-20.

Correspondence to: Prof. Robert H. Gilman, Department of International Health, Johns Hopkins University Bloomberg School of Public Health, 615 N Wolfe St., Rm. W5515, Baltimore MD 21205; fax 410 614-6060; rgilman@jhsph.edu 